\title{
PENGARUH PENGGUNAAN MEDIA PEMBELAJARAN VIDEO TUTORIAL TERHADAP HASIL BELAJAR PEKERJAAN DASAR TEKNIK OTOMOTIF
}

\author{
Hendri Buyung Panadjo, Jenly Manongko, Robert Munaiseche, Hendrik Sumarauw, Leny \\ Ratag \\ Pendidikan Teknik Mesin FATEK Univeritas Negeri Manado \\ hendri.panadj097@gmail.com, jenlymanongko@unima.ac.id, robertmunaiseche@unima.ac.id, \\ hendriksumarauw@unima.ac.id, lenieratag@unima.ac.id
}

\begin{abstract}
ABSTRAK
Riset ini tujuannya buat mengenali terdapat tidaknya pengaruh pemakaian media pendidikan video bimbingan terhadap hasil belajar pekerjaan dasar metode otomotif jurusan TKR di Sekolah Menengah Kejuruan (SMK)) Negeri 2 Bitung. Riset ini memakai desain PretestPosttest Control- Group Design. Populasi pada riset ini ialah segala partisipan didik kelas X jurusan TKR yang sudah menjajaki pendidikan pekerjaan dasar metode otomotif. Ilustrasi pada riset ini berjumlah 60 diambil cocok kebutuhan riset. Setelah itu ilustrasi tersebut diberikan pretest, sehabis itu diberikan treatment secara bertahap. Sehabis diberi treatment, ilustrasi itu diberi Post-test buat mengetahui hasil belajar dikelompok tersebut. Perbandingan hasil Pre-test serta Post-test itu membuktikan hasil pada perlakuan yang sudah diberikan.

Hasil riset ini membuktikan kalau: Ada pengaruh pemakaian media pendidikan video tutorial terhadap hasil belajar pekerjaan dasar metode otomotif siswa kelas X jurusan metode kendaraan ringan di Sekolah Menengah Kejuruan (SMK)) Negeri 2 Bitung bersumber pada analisis yang diperoleh. Ini dibuktikan lewat analisis pengujian hipotesis dimana diperoleh thitung $=10,74$ serta harga ttabel $=1,671553$ dengan $\mathrm{db}(\mathrm{n} 1+\mathrm{n} 2)-2=30+30-2=58$ pada taraf signifikan $\alpha=0,05$. Maksudnya thitung $=10,74$ ttabel $=1,671553$. maksudnya kalau H1 diterima serta $\mathrm{H} 0$ ditolak
\end{abstract}

Kata Kunci: Media Pendidikan Video Bimbingan, Hasil Belajar

\section{ABSTRACT}

This study aims to determine whether there is an effect of the use of video bimbingan learning media on learning outcomes of basic automotive engineering majoring in light vehicle engineering at Sekolah Menengah Kejuruan (SMK) Negera 2 Bitung. This study used a quasi experimental design with a pretest- posttest control-group design. The population in this study were all students of class $X$ majoring in light vehicle engineering World Health Organization had followed basic automotive engineering learning. The sample in this study amounted to 60 taken according to research needs. Then the sample is given a pretest, after which it is given treatment in stages. After being given treatment, the sample was given a posttest to measure learning outcomes in the group. The difference between the pretest and posttest results shows the results of the treatment that has been given.

The results of this study indicate that: There is an effect of the use of tutotial video instructional media on the learning outcomes of basic automotive engineering work for class $X$ students majoring in light vehicle engineering at Sekolah Menengah Kejuruan (SMK) Negeri 2 Bitung based on the analysis obtained. This is evidenced by the analysis of hypothesis testing in which tcount $=10.74$ and ttable price $=1.671553$ with $d b(n 1+n 2)-2=30+30-2=58$ at the significant tingkat $\alpha=0.05$. This means that tcount $=10.74>$ ttable $=1.671553$. This means that $\mathrm{HI}$ is acepted and $\mathrm{HO}$ is rejected

Keywords: Video Bimbingan Lerning Media, Lerning Outcomes 


\section{Pendaluhuan}

Pendidikan adalah salah satu bagian terpenting untuk mewujudkan keberhasilan sebuah negara, sebab pendidikan berhubungan dalam usaha meningkatkan kualitas masyarakat. Dengan pendidikan cara pandang seseorang menjadi positif dan lebih dewasa dalam bertindak. Mutu pendidikan selalu dihubungkan dengan tinggi rendahnya hasil yang ditunjukkan peserta didik dalam mencapai hasil belajar yang maksimal. Pendidikan memiliki pengaruh yang sangat penting untuk meningkatkan kualitas intelektual, spritual, sosial maupun kemampuan profesionalnya. Peningkatan sumber daya manusia yang paling efektif dapat dilakukan dengan pemberdayaan lembaga pendidikan disemua strata. Salah satu lembaga pendidikan adalah sekolah. Berdasarkan tujuan pendidikan di atas, maka pendidikan seharusnya bisa menghasilkan masyarakat yang berkualitas dan kompeten di bidangnya, agar permasalahan-permasalahan krusial lainnya dapat teratasi dengan bijak.

Rendahnya nilai belajar peserta didik di karenakan beberapa sebab yaitu: siswa yang kurang aktif dan kurang memahami konsep pembelajaran. Hal ini dibuktikan dengan aktivitas guru selama kegiatan pembelajaran cenderung lebih banyak mendominasi kelas menggunakan media konvensional dalam pembelajaran. Kondisi ini diduga dapat mengakibatkan rendahnya hasil belajar siswa yang bermuara pada hasil belajar.

Video tutorial adalah media pembelajaran yang bisa memberikan visualisasi yang baik untuk mata pelajaran produktif terutama materi yang membahas tentang membangun jaringan lokal. Dengan adanya video tutorial pembelajaran tersebut diharapkan bisa memberi hasil yang maksimal kaitannya dalam hal penyampaian materi sehingga peserta didik lebih mudah memahami materi.

Fasilitas serta prasarana yang terdapat di Sekolah Menengah Kejuruan (SMK) Negari 2 Bitung dapat dikatakan telah menunjang, tetapi realitasnya guru masih memakai proses pendidikan cuma memakai model pendidikan secara langsung, dimana pendidikan cuma terpusat pada guru, sehingga siswa yang lain sulit menguasai apa yang dipaparkan oleh guru, serta pula siswa sangat bosan serta kurang termotivasi dalam menjajaki proses pendidikan.
Berkaitan dengan perihal tersebut periset mau memakai media pendidikan video bimbingan buat digunakan dalam pendidikan Pekerjaan Dasar Metode Otomotif di kelas X Metode Kendaraan Ringan Sekolah Menengah Kejuruan (SMK) Negara 2 Bitung disebabkan media pendidikan berbasis video bimbingan gampang diperoleh serta efisien serta pula gampang dimengerti oleh siswa. Media pendidikan berbasis video bimbingan mempunyai banyak kelebihan misalnya gampang terbuat, gampang dimengerti, fleksibel, serta dapat dibagikan ataupun diperbanyak kepada siswa. Dengan pemakaian media pendidikan video bimbingan diharapkan bisa tingkatkan partisipasi partisipan didik dalam pendidikan tingkatkan kepemahaman siswa dan yang sangat utama tingkatkan hasil belajar siswa.

\section{Identifikasi Masalah}

Bersumber pada penjelasan latar balik di atas, hingga bisa di identifikasi sebagian kasus selaku berikut:

1. Belum terdapat pemakaian media pendidikan video bimbingan di kelas $\mathrm{X}$ TKR Sekolah Menengah Kejuruan (SMK) Negara 2 Bitung

2. Minimnya pemanfaatan media pembelajaran 3. Masih rendahnya uraian siswa terhadap modul pendidikan.

4. Proses belajar mengajar masih memakai media konvensional.

\section{Batas Masalah}

Buat menanggulangi luasnya kasus, sehingga periset memfokuskan pada Pengaruh Pemakaian Media Pendidikan Video Bimbingan Terhadap Hasil Belajar Pekerjaan Dasar Metode Otomotif di Kelas X TKR Sekolah Menengah Kejuruan (SMK) Negara 2 Bitung.

\section{Rumusan Masalah}

Permasalahan dalam penelitian ini di rumuskan sebagai berikut: Apakah terdapat Pengaruh Penggunaan Media Pembelajaran Video Tutorial terhadap Hasil Belajar Pekerjaan Dasar Teknik Otomotif di kelas X TKR SMK Negeri 2 Bitung.

\section{Manfaat Penelitian}

1. Bagi siswa, dapat meningkatkan hasil belajar.

2. Bagi sekolah, dapat menjadi media pembelajaran alternatif.

3. Bagi peneliti, dapat memberikan pengalaman baru dalam membawakan materi 
pembelajaran dan dapat dijadikan sebagai reverensi bagi peneliti lain dalam menerapkan media pembelajaran serupa.

\section{METODE PENELITIAN}

\section{Waktu dan Tempat Penelitian}

Penelitian dilaksanakan pada semester Ganjil Tahun Ajaran 2019/2020 di SMK Negeri 2 Bitung selama 3 bulan.

\section{Desain Penelitian}

Metode penelitian yang diambil yaitu metode quasi experimental design dengan menggunakan desain penelitian pretest-posttest control-group design.

Tabel 3.1 Pretest-Posttest Control-Group

Design (Arikunto, 2010)

\begin{tabular}{|l|l|l|l|}
\hline Kelompok & $\begin{array}{l}\text { Pre- } \\
\text { test }\end{array}$ & Treatment & $\begin{array}{l}\text { Post- } \\
\text { test }\end{array}$ \\
\hline Eksperimen & $\mathrm{X}_{1}$ & $\mathrm{~T}_{1}$ & $\mathrm{X}_{2}$ \\
\hline Kontrol & $\mathrm{Y}_{1}$ & & $\mathrm{Y}_{2}$ \\
\hline
\end{tabular}

\section{Populasi}

Populasi pada penelitian ini yaitu seluruh siswa kelas X TKR di SMKN 2 Bitung yang berjumlah 102 orang.

Sampel

Populasi yang hendak diambil 2(2) kelas selaku ilustrasi dalam riset. Satu kelas selaku kelas eksperimen, serta yang satunya lagi selaku kelas kontrol. Buat penentuan kelas kontrol serta eksperimen dicoba dengan pengundian secara acak( random). Ada pula ilustrasi dari riset ini meliputi kelas eksperimen serta kelas kontrol. Kelas eksperimen ialah siswa kelas X TKR 1 sebanyak 30 orang serta kelas kontrol ialah kelas X TKR 2 sebanyak 30 orang.

\section{Variabel Penelitian}

Variabel Leluasa (X): media pendidikan berbasis video tutorial

Variabel Terikat (Y): hasil belajar siswa

\section{Definisi Operasional}

1. Model pembelajaran yaitu rencana yang digunakan untuk menyusun langkah- langkah pembelajaran tertentu untuk diterapkan guru agar bertujuan untuk membantu siswa mencapai tujuan pembelajaran.

2. Hasil belajar yaitu suatu pencapaian peserta didik selama menerima dan memahami pengalaman belajar oleh guru.

\section{Sumber Data}

1. Tipe data

Informasi pada riset ini berupa informasi primer dimana informasi primer ialah informasi yang didapat langsung dari nilai siswa.

2. Sumber data

Sumber informasi yang diambil dalam riset ini didapatkan langsung dari siswa SMKN 2 Bitung ialah kelas X TKR 1 serta X TKR 2 yang terdaftar pada tahun ajaran 2019/ 2020.

\section{Tata cara Pengumpulan Data}

Instrument yang dicoba selaku perlengkapan buat memperoleh informasi yang diperlukan oleh periset dalam aktivitas riset ialah observasi serta uji. Uji yang digunakan ialah dalam wujud penjelasan, saat sebelum instrument hasil belajar tersebut digunakan telah dicoba uji validitas.

\section{Metode Analisis Data}

1. Analisis Data Hasil Penelitian

a. Uji Normalitas

Uji normalitas bertujuan buat mengenali apakah penyebaran kedua populasi berdistribusi secara wajar ataupun tidak, buat mengetahuinya hingga periset memakai program pengolahan informasi SPSS 22( Statistical Productand Service Solution) memakai uji normalitas one sample Kolmogorov Smirnov. Kriteria pengujiannya merupakan bila nilai Signifikansi ataupun nilai probabilitas \& 1t; 0.05 hingga distribusi merupakan tidak wajar, sebaliknya nilai Signifikansi ataupun nilai probabilitas 0.05 sehingga distribusi ialah wajar.

b. Uji Homogenitas

Uji homogen diperuntukan buat menguji kesamaan sebagian bagian ilustrasi, maka generalisasi pada populasi bisa dicoba. Pada riset ini, uji homogenitas memakai program pengolah informasi SPSS 22. Kriteria pengujiaanya merupakan bila nilai Signifikansi ataupun nilai probabilitas \&lt; 0. 05 sehingga varian tiap ilustrasi dikatakan tidak homogen, sebaliknya bila nilai Sig.( Signifikansi) ataupun nilai probabilitas 0.05 hingga variansi tiap ilustrasi dikatakan homogen( Santoso, 2003)

c. Uji Hipotesis

Uji t buat varian yang sama memakai rumus Polled Varians selaku berikut: 
t_hitung $=\left(\llbracket \overline{\mathrm{x}} \rrbracket \_1-\llbracket \overline{\mathrm{x}} \rrbracket \_2\right) / \sqrt{ }(\mathrm{s} \& a m p ;(($ $\left.\left.\mathrm{n} \_1-1\right) \mathrm{s} 1^{\wedge} 2+\left(\mathrm{n} \_2-1\right) \mathrm{s} \_2^{\wedge} 2\right) /\left(\mathrm{n} \_1+\mathrm{n} \_1-\right.$ $2)\left(1 / n_{-} 1+1 /\right.$ n_2) $)$

Sebaliknya uji $\mathrm{t}$ buat varian yang berbeda memakai rumus Separated Varians selaku berikut: $t$ hitung $=\left(\bar{x}_{-} 1-\overline{\mathrm{x}} \_2\right) /(\sqrt{ }(1 /$

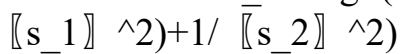

\section{HASIL Riset Serta PEMBAHASAN}

Deskripsi Informasi Hasil Penelitian

Dalam riset ini informasi yang diambil merupakan hasil belajar siswa pada mata pelajaran Pekerjaan Dasar Metode Otomotif.

Informasi Hasil Pre- test serta Post- test Kelas Kontrol

Pada kelas kontrol diperoleh penjelasan skor maksimum pre- test serta post- test kelas kontrol adalah 55 serta 75 , skor minimum pretest serta post- test kelas kontrol ialah 30 serta 40 , jumlah pre- test serta post- test kelas kontrol yaitu

1240 serta 1740 , rata- rata pre- test serta posttest kelas kontrol merupakan 41, 33 serta 58, standar deviasi pre- test serta post- test kelas kontrol ialah 6, 68 serta 9, 52 serta varian pretest serta post- test kelas kontrol ialah 44, 71 serta 90,68 . Informasi hasil pre- test serta posttest kelas kontrol bisa dilihat dibawah ini:

Tabel 4. 1 Ringkasan Informasi Nilai Pre- test serta Post- test Kelas Kontrol

\begin{tabular}{|c|c|c|c|}
\hline \multirow[b]{2}{*}{ No } & \multirow[b]{2}{*}{ Statistik } & \multicolumn{2}{|c|}{ Nilai Statistik } \\
\hline & & Pre-Test & $\begin{array}{c}\text { Post- } \\
\text { Test }\end{array}$ \\
\hline 1 & Jumlah Hasil & 1240 & 1740 \\
\hline 2 & $\begin{array}{l}\text { Nilai } \\
\text { Maksimum }\end{array}$ & 55 & 75 \\
\hline 3 & $\begin{array}{l}\text { Nilai } \\
\text { Minimum }\end{array}$ & 30 & 40 \\
\hline 4 & $\begin{array}{l}\text { Nilai Rata- } \\
\text { Rata }\end{array}$ & 41,33333 & 58 \\
\hline 5 & $\begin{array}{l}\text { Standar } \\
\text { Deviasi }\end{array}$ & 6,686751 & 9,523112 \\
\hline 6 & Varian & 44,71264 & 90,68966 \\
\hline
\end{tabular}

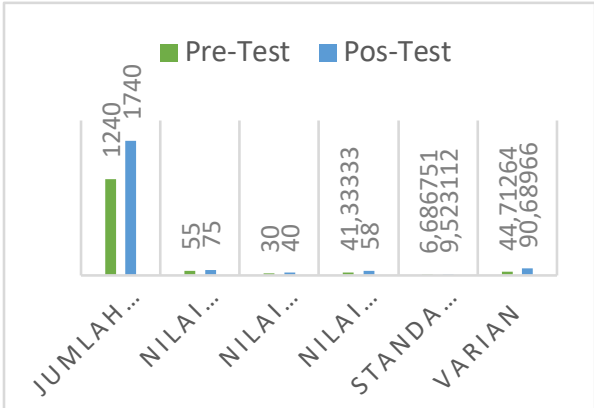

Informasi Hasil pre- test serta post- test kelas Eksperimen

Pada kelas eksperimen diperoleh informasi saat sebelum terdapatnya pendidikan (pre-test) serta kala terdapatnya pendidikan dengan perlakuan memakai model pendidikan Video Bimbingan. Rentang nilai post- test serta pre- test ialah 0-100. Diperoleh penjelasan skor maksimum pre- test serta post- test kelas Eksperimen ialah 60 serta 95, skor minimum pre- test serta post- test kelas eksperimen ialah 35 serta 70, jumlah pre- test serta post- test kelas Eksperimen ialah 1330 serta 2430, nilai rata- rata pre- test serta post- test kelas eksperiemn ialah 44, 33 serta 81, standar deviasi pre- test serta post- test kelas eksperimen ialah 7,15 serta 6,87, serta varian Pre- test serta Post- test kelas kontrol ialah 51,26 serta 47,24 .

Hasil analisis informasi hasil pre-test serta post-test dari kelas eksperimen bisa dilihat dalam tabel 4. 2.

Tabel 4. 2.Rangkuman Informasi Hasil Pre-test serta Post-test Kelas Eksperimen

\begin{tabular}{|c|c|c|c|}
\hline \multirow[b]{2}{*}{ No } & \multirow[b]{2}{*}{ Statistik } & \multicolumn{2}{|c|}{ Nilai Statistik } \\
\hline & & $\begin{array}{l}\text { Pre- } \\
\text { Test }\end{array}$ & $\begin{array}{l}\text { Post- } \\
\text { Test }\end{array}$ \\
\hline 1 & Jumlah Hasil & 1330 & 2430 \\
\hline 2 & $\begin{array}{l}\text { Nilai } \\
\text { Maksimum }\end{array}$ & 60 & 95 \\
\hline 3 & $\begin{array}{l}\text { Nilai } \\
\text { Minimum }\end{array}$ & 35 & 70 \\
\hline 4 & $\begin{array}{ll}\text { Nilai } & \text { Rata- } \\
\text { Rata } & \\
\end{array}$ & 44,3333 & 81 \\
\hline 5 & $\begin{array}{l}\text { Standar } \\
\text { Deviasi }\end{array}$ & 7,15991 & 6,87324 \\
\hline 6 & Varian & 51,2644 & 47,2414 \\
\hline
\end{tabular}




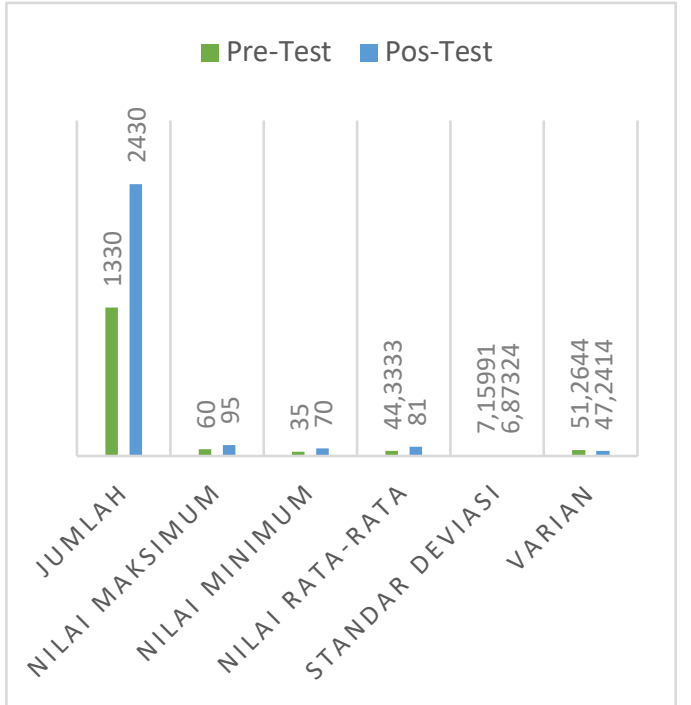

Hasil Penelitian

Uji Normalitas Pre-test Kontrol dan Eksperimen

Hipotesis :

$\mathrm{H}_{0}$ : sampel berasal dari populasi yang berdistribusi normal

$\mathrm{H}_{1}$ : sampel berasal dari populasi yang tidak berdistribusi normal

Kriteria Uji :

1. $\mathrm{H}_{0}$ diterima jika harga signifikansi (Sig.)>

0,05 sehingga $\mathrm{H}_{1}$ ditolak atau,

2. $\mathrm{H}_{1}$ diterima jika harga Signifikansi $<0,05$

sehingga $\mathrm{H}_{0}$ ditolak

Uji Normalitas Post- Test Kontrol serta Eksperimen

Hipotesis:

H0: Ilustrasi berasal dari populasi yang berdistribusi normal

H1: Ilustrasi berasal dari populasi yang tidak berdistribusi normal

Kriteria Uji:

1. H0 diterima bila harga( Sig.) 0,05 sehingga

H1 ditolak ataupun,

2. H1 diterima bila harga( Sig.)\&lt; 0,05 sehingga $\mathrm{H} 0$ ditolak

\section{Uji Homogenitas Pre- Test kelas Kontrol serta Eksperimen}

Hipotesis:

H0: sampel berasal dari populasi yang homogen.

H1: sampel berasal dari populasi yang tidak homogen.
Kriteria Uji:

1. H0 diterima jika harga ( Sig. $)>0,05$ sehingga H1 ditolak atau,

2. H1 diterima jika harga ( Sig. $)<0,05$ sehingga H0 ditolak

Uji Homogenitas Post- Test Kelas Kontrol dan Eksperimen

Hipotesis:

H0: sampel berasal dari populasi yang homogen.

H1: sampel berasal dari populasi yang tidak homogen.

Kriteria Uji:

1. H0 diterima jika harga (Sig.) $>0,05$ sehingga H1 ditolak atau,

2. H1 diterima jika harga (Sig.) $<0,05$ maka H0 ditolak

\section{Uji Hipotesis}

Oleh sebab uji normalitas serta homogenitas telah terpenuhi, sehingga hipotesis bisa dicoba.

Keputusan:

1. Langkah- langkah

H0: $\mu \_$( 1)\&lt; $\mu \_12$

$\mathrm{H} 1: \mu \_1 \mu \_2$

2. Kriteria uji:

$\mathrm{H} 0$ diterima bila nilai Thitung $>$ Ttable serta

H1 ditolak ataupun,

H1 diterima bila nilai Thitung $<$ Ttabel serta

H0 ditolak

Dimana:

$\mu 1=$ rerata hasil belajar partisipan didik kelas eksperimen yang mengenakan media pendidikan video bimbingan terhadap hasil belajar siswa.

$\mu \_2=$ rerata hasil belajar partisipan didik kelas kontrol yang mengenakan media belajar konvensional Probabilitas $\alpha=0,05$

Bersumber pada informasi hasil penghitungan pada lampiran uji hipotesis bisa dikenal kalau harga Thitung $>$ Ttabel merupakan $10,74>1.671553$ hingga disimpulkan kalau ada perbandingan dengan model pendidikan video bimbingan terhadap hasil belajar siswa. Hingga bisa disimpulkan kalau $\mathrm{H} 1$ diterima serta H0 ditolak.

\section{Ulasan Hasil Penelitian}

Dari Analisis Pre- Test dengan PostTest yang telah dijabarkan meyakinkan nilai minimum hasil belajar partisipan didik yang diberi perlakuan dengan mengenakan model 
belajar Video Bimbingan yakni 70 dari nilai sempurna 100, nilai masksimum yang diperoleh yakni 95 dari 100, nilai minimum yang diperoleh dari hasil belajar partisipan didik yang diberi perlakuan dengan mengenakan media pembelajaran konvensional yakni 40 dari nilai sempurna 100 serta nilai maksimum yang diperoleh yakni 75 dari 100 .

Sehabis pembelajaran pekerjaan dasar tata cara otomotif dan nilai diterapkan ditiap tiap- masing- masing kelas dengan tata metode yang berbeda, dimana pembelajaran kelas eksperimen mengenakan media pembelajaran video tutorial kebalikannya kelas kontrol mengenakan tata metode pembelajaran konvensional setelah itu dicoba pengujian posttest.

Dengan melalui uji SPSS kedua sample post- test tersebut berdistribusi normal. Dan selanjutnya karena berasal dari populasi yang berdistribusi normal sehingga dicoba uji homogenitas( uji statistik Levene) dengan taraf signifikansi $5 \%$ dan $\mathrm{H} 1$ diterima dengan kata lain terdapat perbandingan varians populasi data nilai post- test kelas eksperimen dengan post- test kelas kontrol sehingga hasil pengujian homogen menunjukkan taraf Sig. sebesar 0 . 037. Artinya, kelas eksperimen dan kelas kontrol tidak homogen Walaupun nilai pengujian post- test kelas eksperimen dan posttest kelas kontrol tidak homogen, pengujian hipotesis tetap dapat dibuat karena kedua ilustrasi independent maupun tidak silih mempengaruhi.

\section{Kesimpulan}

KESIMPULAN Serta SARAN

Bersumber pada informasi hasil penelitian kalau pemakaian model pendidikan Video Bimbingan berikan pengaruh terhadap hasil belajar siswa dimana diperoleh Thitung $=10,74>$ Ttabel $=1.671553$.

Setelah itu dengan memakai media pendidikan video bimbingan( Eksperimen) dengan hasil rata- rata 81 lebih diatas dari pada yang menjajaki pendidikan konvensional( Kontrol) ataupun yang tidak mempraktikkan media pendidikan video bimbingan dimana nilai rata- rata 58. Bisa disimpulkan pemakaian media pendidikan video bimbingan sangat baik dari pada pemakaian model pendidikan konvensional.

\section{Saran}

Untuk siswa, bisa lebih berani lagi buat mengantarkan ataupun berikan persoalan kepada pemateri ataupun guru bila terdapat yang masih belum mengerti ataupun tidak ketahui dalam proses pendidikan.

Untuk guru, dapat dipakai selaku media pendidikan supaya tingkatkan hasil belajar partisipan didik serta pula menaikkan kreativitas guru dalam mengantarkan modul pelajaran.

Untuk periset, hasil dari riset ini dapat jadi bahan kajian dan perbandingan serta rujukan untuk riset seragam kedepannya.

DAFTAR PUSTAKA

Azhar Arsyad, Media Pendidikan,( Jakarta: PT. RajaGrafindo Persada, 2013)

Dimyati Serta Mudjiono, Belajar Serta Pembalajaran,( Jakarta: Rineka Cipta Tahun2009),

Omear Hamalik, Proses Belajar Mengajar,( Jakarta: Bumi Aksara, 2007),

Purwanto, Penilaian Hasil Belajar,( Yogyakarta: Pustaka Belajar, 2010)

Riyani, Y.( 2012). Faktor- faktor yang Pengaruhi Prestasi Belajar Mahasiswa. Harian EKSOS. 8

Rusman, Deni Kurniawan serta Cepi Riyana, Pendidikan Berbasis Teknologi Data serta Komunikasi,( Jakarta: RajaGrafindo Persada, 2013)

Sharon E. Smaldino, Deborah L. Lowther, James D. Russel, 2012. Instrucsional Technology\&amp; media for Learning, Jakarta: Kencana Prenada.

Slameto. 2003. Belajar serta Faktor- faktor yang Mempengaruhinya. Jakarta: Rineka Cipta.

Surya, Mohammad. 2003. Psikologi Pendidikan serta Pengajaran. Jakarta: Pusataka Bani Quraisy

TKRO YSB STORY Pendidikan Hand Tools http:// www. powtoon. com/ youtube/ Diakses Rabu, 03 Februari 2021, 03. 31 